\title{
Characterization of CPCA-induced action on isolated rat femoral artery
}

\author{
Miroslav Radenković ${ }^{*}$, Radmila Stevanovićㄹ, Milica Stojiljković ${ }^{1}$ Mirko Topalović ${ }^{1}$, Marko Stojanović ${ }^{1}$ \\ From 17th Scientific Symposium of the Austrian Pharmacological Society (APHAR). Joint meeting with the \\ Hungarian Society of Experimental and Clinical Pharmacology (MFT) \\ Innsbruck, Austria. 29-30 September 2011
}

\section{Background}

Adenosine is a purine nucleoside, which modifies different physiological functions, including vascular tone in numerous blood vessels. This effect is a consequence of interaction between adenosine and specific adenosine $A_{1}, A_{2}$ or $A_{3}$ receptors. Still, the relaxant effect of this endogenous nucleoside has been shown on some blood vessels to be mainly dependent on activation of adenosine $A_{2}$ receptors that can be located on endothelial or smooth muscle cells. To examine this assumption the aim of this study was to determine the effects of CPCA (a selective adenosine $A_{2}$ receptor agonist) on the isolated rat femoral artery and to establish whether potassium channels are involved in this action.

\section{Methods}

Experiments were conducted on isolated femoral arteries of male rats. Circular vascular segments were placed in an organ bath with Krebs-Ringer's solution. Concentration-response curves for CPCA were obtained in a cumulative fashion on precontracted artery rings. Tension alterations induced by CPCA were continuously recorded.

\section{Results}

CPCA $(0.1-100 \mu \mathrm{M})$ produced endothelium-dependent relaxation. Incubation of DPCPX (a selective antagonist of $A_{1}$ receptors, $10 \mathrm{nM}$ ) did not influence the control effect of the examined agonist, while SCH 58261 (a selective antagonist of $\mathrm{A}_{2 \mathrm{~A}}$ receptors, $1 \mu \mathrm{M}$ ) significantly reduced CPCA-induced vasodilatation. The maximal vascular response to CPCA was comparable after denudation and incubation of SCH 58261. In the presence of high $\mathrm{K}^{+}(100 \mathrm{mM})$ a significant inhibition of the control CPCA-induced relaxation was recorded. This was not the case after the application of glibenclamide, a blocker of ATP-sensitive $\mathrm{K}^{+}$channels.

\section{Conclusions}

CPCA induced an endothelium-dependent vasodilatation of the examined blood vessel by activation of adenosine $A_{2 \mathrm{~A}}$ receptors, most probably located on the endothelial cells. It can be assumed that the CPCAevoked action was most likely mediated via some endothelium-derived hyperpolarizing factor. However, ATP-sensitive $\mathrm{K}^{+}$channels did not contribute to the overall femoral artery response to CPCA.

\section{Author details}

'Department of Pharmacology, Clinical Pharmacology and Toxicology, Medical Faculty, University of Belgrade, 11129 Belgrade, Serbia. ${ }^{2}$ Institute of Pathology, Medical Faculty, University of Belgrade, 11000 Belgrade, Serbia.

Published: 5 September 2011

doi:10.1186/1471-2210-11-S2-A29

Cite this article as: Radenković et al:: Characterization of CPCA-induced action on isolated rat femoral artery. BMC Pharmacology 2011 11(Suppl 2):A29.

\footnotetext{
* Correspondence: mradenkovic@med.bg.ac.rs

'Department of Pharmacology, Clinical Pharmacology and Toxicology,

Medical Faculty, University of Belgrade, 11129 Belgrade, Serbia

Full list of author information is available at the end of the article
} 